\title{
Seamless Assembly of Biological Parts into Functional Devices and Higher Order Multi-Device Systems.
}

\author{
Jeffrey C Braman* and Peter J Sheffield*.
}

Agilent Technologies, Inc., 11011 North Torrey Pines Road, La Jolla, CA, 92037, USA.

* To whom correspondence should be sent.

\section{Abstract}

A new method is described for the seamless assembly of independent, prefabricated and functionally tested blunt-end, double strand nucleic acid parts (DNA fragments) into more complex biological devices (vectors) and higher order multi-device systems. Individual parts include bacterial selection markers, bacterial origins of replication, promoters from a variety of different species, transcription terminators, shuttle sequences and a variety of " $\mathrm{N}$ " and "C" terminal solubility/affinity expression tags. Pre-assembly modification of parts with DNA modifying enzymes is not required. Seamless assembly of multiple parts is accomplished in a single step using a specialized thermostable enzyme blend in about 30 minutes. Combinatorial assembly of parts is an inherent feature of the new process, substantially simplifying device and system optimization. To underscore the utility of the new process, parts were assembled into several protein expression devices in order to identify the optimal expression construct for a model target gene, as an example of the utility of the assembly process, and a higher order multi- 
device system is also described, for the over-expression of a four-enzyme bio-synthetic pathway, and optimized for end-product accumulation in E. coli as a paradigm for how this assembly process could be used to address the assembly of more complex biological pathways.

\section{Funding}

This work supported exclusively by Agilent Technologies, Inc.

\section{Dedication}

This paper is dedicated to the memory of Dr. Gene Brown, Massachusetts Institute of Technology professor emeritus of biology, a pioneer in the field of intermediary metabolism, former Dean of the MIT School of Science and mentor to JCB. 


\section{Acknowledgement}

The authors would like to thank Dr. Bill Webb at The Scripps Research Institute Center for Metabolomics and Mass Spectrometry for his expertise in performing and analyzing all mass spectrometry data.

\section{Introduction}

The discipline of synthetic biology has greatly benefitted from key enabling technologies such as DNA synthesis and sequencing becoming accessible to more researchers due to the reduction in the previously prohibitive financial entry point. To date however, a third enabling technology, molecular cloning, has not kept pace with technological advances made in DNA synthesis and DNA sequencing. One of the most highly recognized collection of techniques and materials developed to improve conventional cloning of biological parts, devices and systems is "BioBricks" $(1,2)$. Briefly, the "bricks", or parts, of this technology represent cloned DNA sequences possessing defined functions, such as antibiotic resistance and ribosome binding sites. Parts are assembled to create larger devices such as protein expression vectors and several devices are joined into a system such as a biosynthetic pathway. BioBrick devices and systems are constructed by "hierarchical binary assembly" of parts, or "one-brick-at-a-time." More specifically, BioBrick's represent functional double strand DNA molecules housed within carrier plasmids flanked by universal and precisely defined upstream and downstream sequences that 
are technically not part of the BioBrick. These universal sequences contain restriction enzyme recognition sites for one of two closely related enzymes, each having slightly different recognition sequences but upon cleavage generate identical termini (isocaudomers). Linking two BioBricks together requires isolation of the individual parts from their carrier plasmids by specific isocaudomer(s) digestion, end repair in some cases, ligation and finally bacterial transformation. A major drawback to this technique is that BioBrick parts must not contain these restriction enzyme recognition sites within the sequences to be assembled. Also, BioBrick hierarchical binary assembly is time consuming, tedious and not conducive to combinatorial assembly.

Other assembly methods that convert parts into devices also rely on the isolation of parts and devices from dedicated BioBrick-like "destination vectors" (BioBricks [2], SLIC [3], Gibson [4], CPEC [5], SLiCE [6], and In-Fusion [http://www.clontech.com/US/Products/Cloning_and_Competent_Cells/Cloning_Resources/Sele c-tion_Guides/In-Fusion_Cloning_Kits]). In other methods, significant parts manipulation with either one or more Type-II restriction enzymes is required (GoldenGate [7], MoClo [8], GoldenBraid [9]). Alternatively, parts manipulation with T5-exonuclease or a combination of Pfu and Taq DNA polymerases are required for Gibson (4) and DATEL (10) assembly methods, respectively, to create overlaps for subsequent annealing and ligation. In summary, assembly methods are complicated when restriction enzyme specificity must be considered at each stage of parts and devices design. Also, creating small parts between 50 and 250 base pairs with one or more enzymes possessing exonuclease activity is difficult due to the propensity of these enzymes to completely degrade the parts. It is apparent that these limitations curtail combinatorial 
experimental design and significantly slow the process of identifying optimal devices and systems.

Providing prefabricated and functionally validated parts to researchers without the need for retrieval from destination vectors, combined with a seamless protocol conducive to combinatorial assembly of parts into devices and higher order systems, would represent a significant improvement in synthetic biology molecular cloning. This paper describes such a system. Prefabricated parts are provided such that a wide variety of devices can be rapidly assembled. Appropriately chosen parts are combined and assembled in a single-tube reaction creating molecules that transform/transfect and properly function as devices in E. coli, mammalian and yeast (S. cerevisiae) cells. Multiple assembles can be performed in parallel to generate a collection of unique devices that can be used in combination to optimize novel biological systems. The utility of this technology, referred to as "SureVector" (SV), was validated by assembling parts into a collection of devices (plasmids) in order to perform a protein expression screen to identify the best expression tag combination for a model gene of interest (GOI). To further demonstrate the applicability of the SV process, a multi-device system was designed and constructed to reconstitute a four-enzyme biosynthetic pathway in E. coli. This multi-device system enabled the identification of several over-expressing bacterial clones within one week. 


\section{Materials and Methods}

\section{SureVector (SV) Parts}

SureVector parts include bacterial origins of replication [OR], bacterial selectable markers [SM], XP-1 and XP-2 referred to as "Expansion parts" containing sequences allowing replication and selection in a variety of organisms (Saccharomyces cerevisiae and mammalian cells; defined in more detail below), promoters [P] (E. coli, Saccharomyces cerevisiae and mammalian), and protein expression tags [T] (both C-terminal and $\mathrm{N}$-terminal tags are available). Each part is flanked by unique 30 base pair (bp) sequences not found in any global DNA databases, such as NCBI’s Basic Local Alignment Search Tool BLAST (http://blast.ncbi.nlm.nih.gov/Blast.cgi), and allow specific assembly of parts into devices (example shown in Table 1) and ultimately systems. 


\section{XP1 and XP2 Expansion Parts}

XP1 parts contain either the yeast autonomous replication sequence (yARS or 2-micron circle) allowing plasmid replication in S. cerevisiae or a linker derived from a unique nucleotide sequence not possessing a function other than to tether a chosen bacterial origin of replication to an XP2 fragments during parts assembly.

The XP2 parts include either a non-functional tether sequence, as above, or the lacI repressor found in E. coli, or mammalian selection markers or yeast auxotrophic markers, allowing yeast to grow in the absence of an essential amino acid. XP2 parts designed specifically for use in mammalian cells include blasticidin, puromycin or hygromycin selection markers. For yeast, XP2 parts include the auxotrophic markers URA3 and HIS3 and the selection marker for hygromycin resistance. XP2 parts also contain a transcription terminator; either the bovine growth hormone polyA signal (bGH pA) specific for mammalian cells or a rho independent terminator for bacterial transcripts provided by the strong hairpin forming sequence (5'GCCGCCAGCGGAACTGGCGGC-3’). These terminator sequences are positioned and oriented within the XP2 part to terminate transcripts from an upstream GOI.

\section{Large Scale Production and Purification of SV Parts}

Large scale parts synthesis was performed by PCR in 96-well plates using sequence verified master plasmid templates. Each reaction contained $1 \mathrm{ng}$ of plasmid template, $1 \mathrm{x}$ Herculase II 
reaction buffer (Agilent Technologies, Inc.), $0.25 \mathrm{mM}$ of each dNTP, $0.4 \mu \mathrm{M}$ of each PCR primer and $2 \mu \mathrm{l}$ of pre-formulated Herculase II enzyme (Agilent Technologies, Inc.) in a final volume of $100 \mu \mathrm{L}$. Thermocycling conditions were: 1 cycle at $95^{\circ} \mathrm{C}$ for 2 min.; 30 cycles at 95 ${ }^{\circ} \mathrm{C}$ for $20 \mathrm{sec} ., 55^{\circ} \mathrm{C}$ for $20 \mathrm{sec}$. and $72{ }^{\circ} \mathrm{C}$ for $30 \mathrm{sec}$.; 1 cycle at $72{ }^{\circ} \mathrm{C}$ for $3 \mathrm{~min}$. Contents of multiple 96-well plates for each SV part were pooled and purified using AMPure XP magnetic beads according to the manufacturer's instructions (Beckman-Coulter). Correct lengths and purities of SV parts were assessed with an Agilent Technologies, Inc. BioAnalyzer.

\section{General Assembly of SV Parts into Devices}

SV parts designed to assemble into a desired device were combined with a SV adapted GOI part and other reaction components were added as follows: 1x SureVector reaction buffer, $0.25 \mathrm{mM}$ of each dNTP, $5.0 \mathrm{nM}$ of each part (e.g. SM $+\mathrm{OR}+\mathrm{XP} 1+\mathrm{XP} 2+\mathrm{T}+\mathrm{GOI}+\mathrm{P})$ and $1 \mu \mathrm{L}$ of pre-formulated enzyme in a final volume of $20 \mu \mathrm{L}$. Thermocycling of these components consisted of 1 cycle at $95^{\circ} \mathrm{C}$ for $2 \mathrm{~min}$; 8 cycles at $95^{\circ} \mathrm{C}$ for $20 \mathrm{sec} ., 55^{\circ} \mathrm{C}$ for $20 \mathrm{sec}$. and $68^{\circ} \mathrm{C}$ for $30 \mathrm{sec}$.; 1 cycle at $68^{\circ} \mathrm{C}$ for $3 \mathrm{~min}$. Following thermocycling, one unit of $\mathrm{Dpn}$ I restriction enzyme was added to the reaction and incubated for 5 minutes at $37^{\circ} \mathrm{C}$. One $\mu \mathrm{L}$ of the reaction was transformed into XL1-Blue Supercompetent E. coli cells (Agilent Technologies, Inc.) according to instructions and varying amounts $(10,20$ and $50 \mu \mathrm{L})$ of the transformation mixtures were spread onto LB agar plates containing the appropriate antibiotic and incubated at $37^{\circ} \mathrm{C}$ until colonies were easily visualized (12 - 16 hrs.). Device DNA was purified from select 
colonies and either analyzed by restriction digestion, or sequenced to verify correct parts assembly, or used directly in downstream processes.

\section{SV Parts Assembly into Nedd5 Protein Expression Devices}

To demonstrate an obvious use of the new SV cloning method, the human Nedd5 gene was chosen as a model GOI for performing an expression screening experiment. Nedd5 is a mammalian septin known to associate with actin-based structures such as the contractile ring and stress fibers and is involved in the process of cytokinesis in human brain tumors (11), although the specific nature of Nedd5 is not pertinent to this paper. The Nedd5 gene containing a start and a stop codon was adapted by PCR to be SV compatible by using the primers listed below:

N-terminal forward primer 5'-

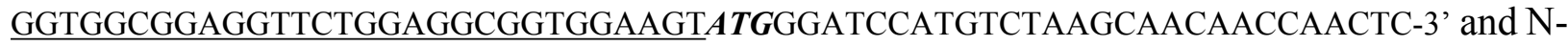
terminal reverse primer 5'- TCGAGGAGATATTGTACACTAAACCAAATGTCACACATGCTGCCCGAGAGCCCCGCTGTCAC-3'.

The Nedd5 gene containing a start codon but lacking a stop codon was adapted by PCR to be SV compatible by using the following primers:

C-terminal forward primer:

5'- CCTTGTTTAAACTTTAAGAGGAGGGCCACCATGGGATCCATGTCTAAGCAACAACCAACTC-3' and

C-terminal reverse primer: 
5'-CCACCGCCTCCAGAACCTCCGCCACCCACATGCTGCCCGAGAGCCCCGCTGTCACTGTCAC-3'

Primers show the start codon or stop codon in bold-italicized type and all primers include unique 30 bases [underlined] for assembly with adjacent parts. The resulting Nedd5 PCR products were used as the model GOI and assembled into a variety of twelve expression constructs each containing a different $\mathrm{C}$ - or $\mathrm{N}$-terminal expression tag. The following parts were used in these assemblies: Amp [SM] + pBR322 [OR] + XP-1 linker + XP-2 lacI + Nedd5 [GOI] with either Cterminal Tags[T] (c-Myc, thioredoxin, streptavidin binding protein, calmodulin binding protein, $\mathrm{His}_{6}$ or hemagglutinin) or N-terminal tags (GST, MBP, His 6 , SBP, CBP, or HisDbsA, calmodulin binding protein or hemagglutinin) + pTac [P] (Refer to section entitled "General assembly of SV parts into devices").

\section{SV Nedd5 Expression Devices Screening}

Nedd5 clones with different expression tags were cultured overnight at $37^{\circ} \mathrm{C}$ with shaking at 250 $\mathrm{rpm}$ in $1 \mathrm{ml}$ of LB broth containing ampicillin $(50 \mu \mathrm{g} / \mathrm{ml})$. The following day, $10 \mathrm{ml}$ cultures of LB broth containing ampicillin $(50 \mu \mathrm{g} / \mathrm{ml})$ were inoculated with these clones and incubated at $37^{\circ} \mathrm{C}$ with shaking at $250 \mathrm{rpm}$ until the $\mathrm{OD}_{600}$, a measure of bacterial growth, reached 0.6

(approximately 1 hour). Protein expression from the $\mathrm{P}_{\text {Tac }}$ promoter was induced by the addition of IPTG to a final concentration of $0.5 \mathrm{mM}$ followed by incubation for 20 hours at $30^{\circ} \mathrm{C}$ with shaking at $250 \mathrm{rpm}$. Volumes of cells equal to $\mathrm{OD}_{600}$ of 3.0 were removed from each culture at time zero (uninduced samples) and after 20 hours of incubation (induced samples). The samples were then centrifuged and cell pellets resuspended in $120 \mu \mathrm{l}$ of $8 \mathrm{M}$ urea. The mixtures were 
vortexed well and incubated at $75^{\circ} \mathrm{C}$ for $5 \mathrm{~min}$. Cell lysates were centrifuged and supernatants analyzed for Nedd5 expression by SDS-gel electrophoresis.

\section{SV Assembly of Parts and Devices into Higher Order Systems expressing DMRL}

SV parts and devices were assembled to reconstitute the four enzyme E. coli biosynthetic pathway (system) for 6,7-dimethy-8-ribityllumazine (DMRL), the fluorescent precursor to riboflavin (rib pathway genes). The DMRL system construction was accomplished by first assembling devices with zero, one or two rib genes. PCR primers used to amplify rib open reading frame gene parts $\mathrm{A}(\mathrm{ribA}-591 \mathrm{bp}), \mathrm{B}(\mathrm{ribB}-654 \mathrm{bp}), \mathrm{D}(\mathrm{ribD}-1104 \mathrm{bp})$ and $\mathrm{E}(\mathrm{ribE}-$ $471 \mathrm{bp)}$ with appended SV overlaps to make them SV compatible were:

E. coli ribA - Gene ID $=945763$

1. ribA_Forward Primer-N-Tag (56 bp):

ggtggcggaggttctggaggcggtggaagt $\boldsymbol{A T} \boldsymbol{G C A G C T T A A A C G T G T G G C A G A A G C ~}$

2. ribA_Reverse Primer-RBS (67 bp):

gaaattgttaaattatttctagattcgaaaggagctcgaattcTTATTTGTTCAGCAAATGGCCCAT

E. coli ribB - Gene ID $=947526$

1. ribB_Forward Primer-N-Tag (56 bp)

ggtggeggaggttctggaggcggtggaagt $\boldsymbol{A T} \boldsymbol{T}$ AATCAGACGCTACTTTCCTCTTT

2. ribB_Reverse Primer-RBS (68 bp):

gaaattgttaaattatttctagattcgaaaggagctcgaattcTCAGCTGGCTTTACGCTCATGTGCC

E. coli ribD - Gene ID $=945620$ 
1. ribD_Forward Primer-RBS (73 bp):

ttcgaatctagaaataatttaacaatttcacataaaggaggtaaata $\boldsymbol{A T G C A G G A C G A G T A T T A C A T G G C G C G ~}$

2. ribD_Reverse Primer (54 bp)

ctcgaggagatattgtacactaaaccaaatgTCATGCACCCACTAAATGCAGGC

E. coli $\mathrm{ribE}-\mathrm{Gene}$ ID $=946453$

1. ribE_Forward Primer-RBS (74 bp):

ttcgaatctagaaataatttaacaatttcacataaaggaggtaaata $\boldsymbol{A T G A A C A T T A T T G A A G C T A A C G T T G C ~}$

2. ribE_Reverse Primer: (55 bp)

ctcgaggagatattgtacactaaaccaaatgTCAGGCCTTGATGGCTTTCAATAC

Two sets of bi-cistronic devices were designed and assembled, one containing the ribA and ribD genes and the other containing the ribB and ribE genes. A ribosome binding site (RBS) was included in the 3' region of the ribA and ribB genes downstream of their native stop codon and the same sequence was also included in the 5 ' region upstream of the ATG start codon of the ribD and ribE genes. This RBS sequence was used as the overlap by which the ribD and ribE genes were positioned downstream of ribA and ribB genes, respectively. The intended outcome was to place two rib genes under control of one promoter and couple expression of the upstream and downstream rib genes via a second RBS between the two rib genes. This was done to attempt to balance expression levels of the individual rib genes. This second RBS overlap region between the rib genes was designed in such a way that the downstream rib gene was not in the same reading frame as the upstream rib gene thus preventing two gene products in the same device from becoming physically linked. An additional stop codon was also added to each upstream rib gene to further guard against translation read-through. Bi-cistronic vectors of this type have been used previously for preparation of nuclear receptor partners RAR and RXR (12) 
and for the analysis of NFФB p50/p65 heterodimer (13). Devices lacking either the upstream or downstream rib gene parts were correctly assembled into circular molecules using $90 \mathrm{bp} \mathrm{N}$ terminal and C-terminal "Non-Coding" linker parts NC-N and NC-C, respectively, and were made by overlap extension (14):

N-terminal "NC" replaces ribA or ribB parts.

rib - "NC" N-term_Forward ggtggcggaggttctggaggcggtggaagtgaaactgcactcatcgtccetcgaggagct rib - "NC" N-term_Reverse gaaattgttaaattatttctagattcgaagagctcctcgagggacgatgagtgcagtttc

C-terminal "NC" replaces ribD or ribE parts.

rib - "NC" C-term_Forward ttcgaatctagaaataatttaacaatttcacataaaggaggtatagacagcatacgagtc

rib - "NC" C-term_Reverse ctcgaggagatattgtacactaaaccaaatgactcgtatgctgtctatacctcctttatg

Bi-cistronic devices that only contain a single rib gene required either a $\mathrm{NC}-\mathrm{N}$ or $\mathrm{NC}-\mathrm{C}$ part in lieu of the corresponding rib gene part. Three standard parts were used in both sets of rib devices; the $\mathrm{T} 7$ promoter-HIS 6 , XP1 linker and XP2 lacI. These 3 standard parts were used in various combinations with either the ampicillin or kanamycin selectable markers and the pBR322 or p15a bacterial origins of replication. Therefore, all SV rib devices were assembled from just seven SV parts. A total of 18 device level plasmids were constructed. These system level devices were designated by letter-number codes. "K" devices consisted of the kanamycin resistance marker (kan), the p15a origin of replication and either zero, one or two rib genes. "A" devices consisted of the ampicillin resistance marker (amp), the pBR322 origin of replication and either zero, one or two rib genes (Table 2). Higher order systems were created using various 
combinations of these device level plasmids by the co-transformation of two devices. For example, devices $\mathrm{K} 6$ and A7 resulted in co-expression of ribA-ribD genes from the K6 device and ribB-ribE genes from the A7 device. Combinations of devices were transformed into Agilent BL21(Gold) DE3 E. coli and spread onto LB- agar plates containing $100 \mu \mathrm{g} / \mathrm{ml}$ each of kanamycin and ampicillin (LB-kan-amp) plus $0.5 \mathrm{mM}$ IPTG. Plates were incubated at $37^{\circ} \mathrm{C}$ for 12 to 18 hours and examined under UV light to identify DMRL expressing clones (systems) as evidenced by fluorescent colonies surrounded by fluorescent halos.

\section{Validation of DMRL System Synthesis - Assay, Purification and MS Analysis}

Monitoring clones for DMRL synthesis on agar plates was straightforward as the DMRL fluoresces within colonies and is secreted into the surrounding media creating fluorescent halos around DMRL positive colonies. DMRL production from clones cultured in liquid media was also straightforward as the compound possesses a characteristic visible light absorption spectrum with $\lambda$ max $\mathrm{OD}_{490}(15)$ that can be measured in cell free supernatants. Validation of DMRL synthesis required its production, purification and analytical characterization. Clone K6A7 produced pronounced fluorescent colony-halos and was chosen for this purpose. A single colony was inoculated into $3 \mathrm{ml}$ of LB-kan-amp liquid media and incubated overnight at $37^{\circ} \mathrm{C}$ with shaking at $250 \mathrm{rpm}$. A $2.0 \mathrm{ml}$ sample of this culture was inoculated into a $500 \mathrm{ml}$ Erlenmeyer flask containing $100 \mathrm{ml}$ of LB-kan-amp and incubation continued as before until the $\mathrm{OD}_{600}$ value reached 0.35 . IPTG was added to a final concentration of $0.5 \mathrm{mM}$ and incubation continued for an additional 18 hours. Cells were removed by centrifugation and acetic acid added to the 
supernatant to a final concentration of $5 \%$. This sample was applied to a $2.5 \times 3.5 \mathrm{~cm}$ column of Florisil (Sigma-Aldrich) equilibrated with 5\% acetic acid. The column was washed with one liter of 5\% acetic acid and DMRL eluted with $100 \mathrm{ml}$ of $3 \%$ pyridine. Solvent was removed by evaporation and the residue suspended in $5 \mathrm{ml}$ of water. This sample was applied to a $2.5 \times 35$ cm column of chromatography grade cellulose (Sigma-Aldrich) equilibrated with water and DMRL was eluted with water. Forty milligrams of DMRL were recovered from $0.8 \mathrm{~g}$ of cells (wet weight) and was analyzed by mass spectrometry. The sample was run on an Agilent 6538 QTOF coupled to an Agilent 1100/1200 lc stack. The column was a Zorbax SB-C18 0.5 x 150 $\mathrm{mm}$. Flowrate $=20 \mu \mathrm{l} / \mathrm{min}$. Injection volume $=5 \mu \mathrm{l}$. Solvent $\mathrm{A}$ was $\mathrm{H}_{2} \mathrm{O}-0.1 \%$ formic acid and solvent B was acetonitrile - 0.1\% formic acid. Gradient: T0: 95\% A - 5\% B; T10: 75\% A - 25\% B; T12: 50\% A - 50\% B; T15: 5\% A - 95\% B; T20: off. Five min. re-equilibration time. For the ms run, a range from $\mathrm{m} / \mathrm{z}=85$ to $\mathrm{m} / \mathrm{z}=1100$ was scanned. For the $\mathrm{ms} / \mathrm{ms}$ run, $\mathrm{m} / \mathrm{z} 327.1$ was targeted, with three different collision energies: ce $=10 \mathrm{~V}$, ce $=20 \mathrm{~V}$, and ce $=40 \mathrm{~V}$.

\section{Quantities and Rates of DMRL Synthesis from Devices and Systems}

Single colonies from devices and systems listed in Table 2 were purified by re-streaking onto fresh LB-kan-amp plates without IPTG. Three colonies from each plate were cultured overnight at $37^{\circ} \mathrm{C}$ with shaking at $250 \mathrm{rpm}$ in separate tubes containing $3 \mathrm{ml}$ of LB-kan-amp. The next day, one hundred microliters of each culture were added to $4.9 \mathrm{ml}$ of LB-kan-amp and incubated until $\mathrm{OD}_{600}$ reached between 0.3 and 0.5 . IPTG was added to a final concentration $0.5 \mathrm{mM}$ and incubation continued for three hours after which $\mathrm{OD}_{600}$ values were re-measured. Cultures were 
centrifuged to remove cells and $\mathrm{OD}_{409}$ values of supernatants obtained. $\mathrm{OD}_{409}$ values were normalized relative to $\mathrm{OD}_{600}$ values measured post IPTG addition and the resulting numbers compared. DMRL was synthesized exclusively by clones containing all four rib genes (two devices each expressing two rib genes) - systems K6A7, K7A6, K8A9, K9A8.

DMRL synthesis rates of systems K6A7, K7A6, K8A9, K9A8 and negative control K5A5 were obtained by inoculating single colonies into $5 \mathrm{ml}$ of LB-kan-amp media followed by overnight incubation at $37^{\circ} \mathrm{C}$ with shaking at $250 \mathrm{rpm}$. One $\mathrm{ml}$ of these starter cultures was inoculated into separate $250 \mathrm{ml}$ flasks each containing $49 \mathrm{ml}$ of LB-kan-amp. Incubation at $37^{\circ} \mathrm{C}$ with shaking at $250 \mathrm{rpm}$ continued until $\mathrm{OD}_{600}$ values reached between 0.3 and 0.5 . IPTG was added to a final concentration of $0.5 \mathrm{mM}$ and incubation continued. At regular intervals, $1.0 \mathrm{ml}$ samples were retrieved from each culture and $\mathrm{OD}_{600}$ values measured. Samples were then centrifuged to remove cells and $\mathrm{OD}_{409}$ values of supernatants obtained. $\mathrm{OD}_{409}$ values were normalized relative to $\mathrm{OD}_{600}$ values measured post IPTG addition and the resulting numbers compared.

\section{Results}

\section{Design Features of SV Parts and Assembly Process}

The key design features of SV parts, ensuring precise and ordered joining, are the unique $30 \mathrm{bp}$ sequences incorporated into each PCR primer used to generate a part (see Materials and Methods 
section). Figure 1 schematically represents how seven SV parts align and overlap due to this design feature.

Assembling parts listed in

Table 1 in the manner described in the Materials and Methods section and in the Figure 1 legend generated devices expressing GOI's with an N-terminal fusion protein: -Bacterial Selectable Marker-Bacterial Origin of Replication-XP1-XP2-GOI $\leftarrow$ Expression Tag $\leftarrow$ Promoter-

$(\leftarrow$ denotes direction of promoter and gene expression)

The assembly mechanism of linking parts into higher order devices is represented in Figure 2.

Parts are denatured and adjacent parts anneal due to the $30 \mathrm{bp}$ overlaps. Exposed 3'-OH ends are partially extended by a polymerase resulting flaps that are digested by an endonuclease and covalently joined by a ligase.

Figure 3 represents the combinatorial assembly power of the SV process. Different functional parts are rapidly assembled into multiple configurations in parallel assembly experiments to determine the best organization for, in this case, expression of single GOI. 


\section{SV Nedd5 Expression Devices Screening}

SDS-page analysis of twelve Nedd5 expression devices, fused with N- or C- terminal tags identified the best expression constructs (green arrows shown in Figures $4 \mathrm{a}$ and $\mathrm{b}$ highlight proteins from induced cultures). Quantities of expressed fusion proteins varied with the type of expression tag and were highest with N-terminal tagged MBP/Nedd5, HisDbsA/Nedd5, and CBP/Nedd5 devices and C-terminal tagged Nedd5/SBP, Nedd5/c-myc and Nedd5/His6 devices. Lesser quantities of fused proteins were expressed as N-terminal tagged GST/Nedd5 and His6/Nedd5 devices and C-terminal tagged Nedd5/Thioredoxin and Nedd5/CBP devices. The least quantities of fusion Nedd5 were N-terminal tagged SBP/Nedd5 and C-terminal tagged Nedd5/HA devices. It is worth emphasizing that this protein expression screening experiment, starting from assembly of parts into devices and analyzing protein expression was completed in less than three days.

\section{Re-Creating a Biosynthetic Pathway}

The utility of SV parts assembly into devices and ultimately higher order systems was demonstrated by recreating the $E$. coli biosynthetic pathway for 6,7-dimethy-8-ribityllumazine (DMRL), the fluorescent precursor to riboflavin (Figure 5; 16). DMRL is synthesized by four unique enzymes (expressed from ribA, ribB, ridD and ribE genes) and substrates. The critical initial substrates for this pathway are GTP and ribulose-5' -phosphate (R5P). They are funneled 
through a "nucleotide conversion route" (NCR), a "sugar conversion route" (SCR) and a

"converging condensation route" (CCR). The NCR starts by the hydrolytic removal of carbon atom 8 from the imidazole ring of GTP by GTP Cyclohydrolase II (ribA gene product; 17) yielding 2,5-diamino-6-ribosylamino-4(3H)-pyrimidinone-5' -phosphate (DARPP). DARPP is converted to 5-amino-6-ribitylamino-2,4(1H,3H)-pyrimidinedione-5' -phosphate (ARPP) by diaminohydroxyphosphoribosylaminopyrimidine deaminase/5-amino-6-ribitylamino-

2,4(1H,3H)-pyrimidinedione reductase (ribD gene product; 18, 19), a "fused" enzyme possessing both NCR and SCR-relevant activities. As the enzyme name describes, the nucleotide base of DARPP is deaminated followed by reduction of the ribosyl moiety to ribityl with NADPH serving as reductant. Separately, L-3,4-dihydroxy-2-butanone-4-phosphate synthase, an enzyme exclusively in the SCR (ribB gene product; 20) converts ribulose-5' -phosphate (R-5-P) to L-3,4dihydroxy-2-butanone-4-phosphate (DHBP) and formate. Both ARPP and DHBP are dephosphorylated and enter the CCR via DMRL synthase (ribE gene product; 21) resulting in DMRL.

\section{Pathway Construction}

DMRL pathway construction was accomplished by first assembling SV parts into devices (Table 2) containing zero, one and two ("bi-cistronic") rib genes. PCR primers used to amplify rib gene parts A, B, D and E are shown in Materials and Methods. They allowed amplification of rib open reading frames ribA - 591 bp, ribB - 654 bp, ribD - 1104 bp and ribE - 471 bp with appended correct overlaps to make them SV compatible. Two sets of bi-cistronic devices, one containing the ribA and ribD genes and the other containing the ribB and ribE genes were also designed and 
assembled (Table 2). Ribosome binding sites (RBS) were designed and incorporated into the 3'and 5' flanking regions of the rib genes and subsequently used as unique overlaps between the genes such that ribD and ribE genes were positioned downstream of the ribA and ribB genes, respectively. The intended outcome of placing two rib genes under control of one T7 promoter and coupling expression of the upstream and downstream rib genes was balanced expression levels. The RBS placed in the 5' regions of both ribD and ribE genes promoted downstream rib gene translation efficiency. The RBS overlap between the upstream and downstream rib genes was designed so that the downstream rib genes were out of frame with the upstream rib genes thus preventing two gene products in the same device from becoming physically linked. An additional stop codon was also added to each upstream rib gene as an added prevention to translation read-through. Bi-cistronic devices of this type have been used previously for preparation of nuclear receptor partners RAR and RXR (13) and for the analysis of NFФB p50/p65 heterodimer (14). SV devices lacking one or both rib genes were also assembled using N-terminal and C-terminal "Non-Coding" parts; $\mathrm{NC}-\mathrm{N}$ and $\mathrm{NC}-\mathrm{C}$, respectively (Table 2). Zero or single rib gene control devices required either an NC-N or NC-C part, or both in the case of the double negative control, in lieu of a rib gene part. Common SV parts used in both sets of rib devices were the T7 promoter-HIS 6 , XP1 linker and XP2 lacI (allowing IPTG induction of rib gene devices expression) in addition to various combinations of ampicillin and kanamycin selectable markers with pBR322 or p15a bacterial origins of replication. Therefore, all 18 SV rib device plasmids were assembled from just 7 seven SV parts, not including the rib gene parts.

Table 2 devices were transformed either individually or in various co-transformation scenarios (Table 3) into Agilent BL21(Gold) DE3 E. coli and spread onto LB- agar plates containing 100 
$\mu \mathrm{g} / \mathrm{ml}$ each of kanamycin and ampicillin (LB-kan-amp) plus $0.5 \mathrm{mM}$ IPTG. Plates were incubated at $37^{\circ} \mathrm{C}$ for twelve to eighteen hours. All colony devices and systems were easily monitored for DMRL synthesis by irradiating plates with UV light and visualizing fluorescent colonies surrounded by fluorescent halos. DMRL producing colony systems contained all four rib genes (Figure 6 - left panel). Colonies containing only 1, 2 or 3 rib genes, as well as the double negative control lacking all 4 rib genes (clone K5A5 assembled with NC-N and NC-C parts), did not produce DMRL (Figure 6 - right panel; no fluorescent colonies and halos).

\section{Characterization of DMRL Synthesized by SV rib System K6A7.}

DMRL synthesized and purified from system K6A7 (Table 3) was characterized by mass spectrometry (see Materials and Methods). For the $\mathrm{ms}$ run, a range from $\mathrm{m} / \mathrm{z}=85$ to $\mathrm{m} / \mathrm{z}=1100$ was scanned. The theoretical $\mathrm{m} / \mathrm{z}$ value for DMRL is 327.12990 and the observed $\mathrm{m} / \mathrm{z}$ value was 327.12914 (data not shown). In addition, for the $\mathrm{ms} / \mathrm{ms}$ run the $\mathrm{m} / \mathrm{z}$ value of 327.1 was targeted, using three different collision energies at $10 \mathrm{~V}, 20 \mathrm{~V}$, and $40 \mathrm{~V}$. The expected exact mass of fragmented DMRL was 192.06 and the observed value was 192.07 (data not shown) thus confirming that SV system K6A7 produced DMRL.

\section{Quantities and Rates of DMRL Synthesis from DMRL Devices and Systems}


Figure 7a confirms that only SV systems K6A7, K7A6, K8A9, K9A8, each containing two rib gene devices expressing all four rib genes, produced DMRL. Clones K6A7 and K7A6 produced the highest levels of DMRL and most rapidly (Figures 7a and b). These systems are composed of devices K6 and A6 expressing enzymes from ribA and ribD genes, respectively, both in the NCR path. ribA is positioned immediately downstream of the T7 promoter. Devices $\mathrm{K} 7$ and A7 express enzymes from ribB and ribE genes, respectively, with ribB in the SCR path and ribE in the CCR path. ribB is positioned immediately downstream of the T7 promoter. Total DMRL accumulation and slower synthesis rates are similar in systems K8A9 and K9A8. These systems are composed of devices $\mathrm{K} 8$ and A8 expressing enzymes from ribA and ribE genes, respectively, with ribA in the NCR path and ribE in the CCR path. ribA is positioned immediately downstream of the T7 promoter. Systems composed of devices K9 and A9 express enzymes from ribB and ribD genes, respectively, with ribB in the SCR path and ribD in the NCR path. ribB is positioned immediately downstream of the $\mathrm{T} 7$ promoter. How these system configurations resulted in different totals and rates of DMRL synthesis were not examined.

\section{Discussion}

A new method (SureVector) for seamless assembly of biological parts into functional devices and higher order systems is presented that takes advantage of principles learned from prefabrication engineering design and assembly. These are: (1) Functional DNA parts are manufactured and quality controlled at a location away from the assembly site (Agilent Technologies, Inc.; (2) Parts, other requisite assembly materials and detailed assembly 
instructions are delivered to the site of construction (the research laboratory) for assembly; (3)

from a synthetic biology standpoint, processes (1) and (2) enable rapid and reliable combinatorial assembly of desired devices destined for introduction into E. coli, mammalian and yeast cells. The salient features of this new method were demonstrated by constructing a set of protein expression devices to identify the best device for the expression of a target GOI (Nedd5) and a higher order system was constructed to recreate a four-gene biosynthetic pathway system (DMRL). The combinatorial assembly power of this process was utilized in developing the DMRL expression system. A total of 18 protein expression devices were assembled in one day possessing zero, one or two rib gene (bi-cistronic) parts. Expression screening was initiated the following day and positive systems were selected for structural and functional testing in less than one week. While assembled devices were being sequenced for validation of their structural integrity, DMRL was purified and characterized by mass spectrometry. Experiments were also performed to determine optimal DMRL synthesis rates and maximum production. The same type of project out sourced to a third-party vendor would have taken several months to complete (previous experience). While optimizing DMRL production was not the goal of these experiments, it is worth noting that $40 \mathrm{mg}$ of DMRL was purified from $100 \mathrm{ml}$ of media collected after growth of $0.8 \mathrm{~g}$ (wet weight) of $E$. coli clone K6A7. In stark contrast, Maley and Plaut (15) required $5 \mathrm{~kg}$ of the mold A. gossypii to obtain $160 \mathrm{mg}$ of DMRL.

The combinatorial power, simplicity and assembly accuracy of the SureVector process will facilitate building many "multi-device" systems including unique biochemical synthetic pathways and novel regulatory circuits. Production of fine chemical intermediates and endproducts represents an obvious high-value application. 


\section{References:}

1. Knight, T.F. (2003) Idempotent vector design for standard assembly of BioBricks. Tech. Report., MIT Synthetic Biology Working Group Technical Reports.

2. Shetty, R.P., Endy, D. and Knight, T.F. Jr. (2008) Engineering BioBrick vectors from

BioBrick parts. J. Biol. Eng. 2, 5.

3. Li, M.Z. and Elledge, S.J. (2007) Harnessing homologous recombination in vitro to generate recombinant DNA via SLIC. Nature Methods, 4, 251 - 256. 
4. Gibson, D.G., Young, L., Chuang, R-Y., Venter, J.C., Hutchison, C.A. and Smith, H.O. (2009)

Enzymatic assembly of DNA molecules up to several hundred kilobases. Nature Methods. 6, 343

-345 .

5. Quan, J. and Tian, J. (2009) Circular polymerase extension cloning of complex gene libraries and pathways. PLoS ONE 4(7): e6441.

6. Yongwei, Z., Werling, U. and Edelmann, W. (2012) SLiCE: a novel bacterial cell extractbased DNA cloning method. Nucleic Acids Res. 40 (8): e55.

7. Engler, C., Gruetzner, R., Kandzia, R. and Marillonnet, S. (2009) Golden Gate Shuffling: A one-pot DNA shuffling method based on Type IIs restriction enzymes. PLoS ONE 4(5): e5553.

8. Weber, E., Engler, C., Gruetzner, R., Werner, S. and Marillonnet, S. (2011) A modular cloning system for standardized assembly of multigene constructs. PLoS ONE 6(2): e16765.

9. Sarrion-Perdigones, A., Falconi, E.E., Zandalinas, S.I., Juárez, P., Fernández-del-Carmen, A., Granell, A. and Orzaez, D. (2011) GoldenBraid: an iterative cloning system for standardized assembly of reusable genetic modules. PLoS ONE 6 (7): e21622. 
10. Jin, P., Ding, W., Du, G., Chen, J. and Kang, Z. (2016) DATEL: A scarless and sequenceindependent DNA assembly method using thermostable exonucleases and ligase. ACS Synth. Biol. 5 (9): 1028-32.

11. Kinoshita, M., Kumar, S., Mizoguchi, A., Ide, C., Kinoshita, A., Haraguchi, T., Hiraoka, Y. and Noda, M. (1997) Nedd5, a mammalian septin, is a novel cytoskeletal component interacting with actin-based structures. Genes Dev. 11 (12): 1535-47.

12. Sheffield, P.J. (2001) Preparation and crystal structure of the recombinant $\alpha 1 / \alpha 2$ catalytic heterodimer of bovine brain platelet-activating factor acetylhydrolase Ib. Protein Engineering 14: 513-519.

13. Sheffield, P. J. Oliver, C.J., Kremer, B.E., Sheng, S., Shao, Z. and Macara, I. G. (2003) Borg/Septin interactions and the assembly of mammalian septin heterodimers, trimers, and filaments. J. Biol. Chem. 278: 3483-3488.

14. Anton V. Bryksin and Matsumura I (2010) Overlap extension PCR cloning: a simple and reliable way to create recombinant plasmids. Biotechniques 48 (6): 463-465.

15. Maley, G.F. and Plaut, G.W.E. (1959) The isolation, synthesis and metabolic properties of 6,7-dimethyl-8-ribityllumazine. J. Biol. Chem. 234: 641-647. 
16. Zhenquan, L., Lin, Z., Xu, Z., Li, Y., Wang, Z., Chen, T. and Zhao X. (2014) Metabolic engineering of Escherichia coli for the production of riboflavin. Microbial Cell Factories 13: 104.

17. Foor, F. and Brown, G.M. Purification and properties of guanosine triphosphate cyclohydrolase II from Escherichia coli. J. Biol. Chem. 250: 3545 - 3551 (1975).

18. Burrows, R.B. and Brown, G.M. Presence in Escherichia coli of a deaminase and a reductase involved in biosynthesis of riboflavin. J. Biol. Chem. 136: 657 - 667 (1978).

19. Richter, G., Fischer, M., Krieger, C., Eberhardt, S., Lüttgen, H., Gerstenschläger, I. and Bacher A. (1997) Biosynthesis of riboflavin: characterization of the bifunctional deaminasereductase of Escherichia coli and Bacillus subtilis. J. Bact. 179: 2022 - 2028.

20. Volk, R. and Bacher, A. (1990) Studies on the 4-carbon precursor in the biosynthesis of riboflavin. J. Biol. Chem. 265: 19479 - 19486. 
21. Mörtl, S., Fischer, M., Richter, G., Tack, J., Weinkauf, S. and Bacher, A. (1996) Biosynthesis of riboflavin. Lumazine synthase of Escherichia coli. J. Biol. Chem. 271: $33201-33207$.

Figure and Table Legends:

Figure 1. Schematic of a seven SV part assembly into a GOI Expressing Device. Different colored open rectangles highlight unique $30 \mathrm{bp}$ overlaps between functional parts. Sequences represented by the two end rectangles (red) also overlap. The mixture of parts is treated with the SureVector enzyme assembly blend resulting in a device, represented by the closed circle that will transform, replicate and express a GOI in E.coli.

Figure 2. Schematic Showing How Adjacent SV Parts are Assembled; Parts A and B

Possess Homologous Ends. Following denaturation and annealing, resulting free 3' ends are extended, "flaps" digested and the two parts ligated.

Figure 3. Collection of SV Parts and Assembly Design. A variety of parts and GOI's can be assembled into many functional devices.

\section{Figure 4a. SDS-PAGE Gel of SV Nedd5 Expression Devices with Different N-Terminal}

Tags. $\mathrm{M}=$ protein molecular weight marker; Uni = Uninduced sample; Induced samples. Green stars $(\star)$ denote expressed N-terminal tagged Nedd5-fusion proteins. 


\section{Figure 4b. SDS-PAGE Gel of SV Nedd5 Expression Devices with Different C-Terminal}

Tags. $\mathrm{M}=$ protein molecular weight marker; $\mathrm{UI}=$ Uninduced samples; $\mathrm{Ind}=$ Induced samples. Green stars $(\star)$ denote expressed C-terminal tagged Nedd5-fusion proteins.

Figure 5. DMRL Biosynthetic Pathway. The imidazole ring of GTP is hydrolytically removed by GTP Cyclohydrolase II (rxn. 1; ribA) yielding 2,5-diamino-6-ribosylamino-4(3H)pyrimidinone-5' -phosphate (DARPP), formate and pyrophosphate. DARPP is converted to 5amino-6-ribitylamino-2,4(1H,3H)-pyrimidinedione-5' -phosphate (ARPP) by fused diaminohydroxyphosphoribosylaminopyrimidine deaminase/5-amino-6-ribitylamino2,4(1H,3H)-pyrimidinedione reductase (rxns. 2; both ribD). Separately, ribulose-5-phosphate (R5P) is converted to L-3,4-dihydroxy-2-butanone-4-phosphate (DHBP) and formate by L-3,4dihydroxy-2-butanone-4-phosphate synthase (rxn. 3; ribB). ARPP and DHPB are dephosphorylated and then condensed by DMRL synthase (rxn. 4; ribE) producing 6,7-dimethyl8-ribityllumazine (DMRL).

\section{Figure 6. Co-Transformation of Two SV Compatible Devices Containing All 4 rib}

Biosynthetic Genes Results in DMRL Synthesis. Devices K6 and A7 (see Table 2) were cotransformed into Agilent BL21(Gold)DE3 E.coli and spread onto LB-kan-amp-IPTG plates. Resulting colonies were examined under unfiltered UV light. All resulting K6A7 systems contained four rib genes and produced DMRL as evidenced by fluorescent colonies with fluorescent halos. Control (device K5A5) through three rib genes (see Table 2) did not produce DMRL as no fluorescent halos were detected. 


\section{Figure 7 (a) Total Quantites of DMRL Synthesis from Devices and Systems.}

Single colonies from devices and systems listed in Table 3 were purified by re-streaking onto fresh LB-kan-amp plates without IPTG. Three colonies from each plate were cultured in separate tubes containing $3 \mathrm{ml}$ of LB-kan-amp. One hundred microliters of each culture were added to 4.9 $\mathrm{ml}$ of LB-kan-amp and incubated until OD600 reached between 0.3 and 0.5 . IPTG was added to a final concentration $0.5 \mathrm{mM}$ and incubation continued for three hours after which OD600 values were re-measured. Cultures were centrifuged to remove cells and OD409 values of supernatants obtained. OD409 values were normalized relative to OD600 values measured post IPTG addition and the resulting numbers compared. DMRL was synthesized exclusively by systems containing two devices each expressing two rib genes -systems K6A7, K7A6, K8A9 and K9A8.

\section{Figure 7 (b) DMRL Synthesis Rates.}

DMRL synthesis rates of systems K6A7, K7A6, K8A9, K9A8 and negative control K5A5 were obtained by inoculating single colonies into $5 \mathrm{ml}$ of LB-kan-amp media followed by overnight incubation at $37^{\circ} \mathrm{C}$ with shaking at $250 \mathrm{rpm}$. One $\mathrm{ml}$ of these starter cultures was inoculated into separate $250 \mathrm{ml}$ flasks each containing $49 \mathrm{ml}$ of LB-kan-amp. Incubation at $37^{\circ} \mathrm{C}$ with shaking at $250 \mathrm{rpm}$ continued untilOD600 values reached between 0.3 and 0.5 . IPTG was added to a final concentration of $0.5 \mathrm{mM}$ and incubation continued. At regular intervals, $1.0 \mathrm{ml}$ samples were retrieved from each culture and OD600 values measured. Samples were then centrifuged to remove cells and OD409 values of supernatants obtained. OD409 values were normalized by dividing by the OD600 values and these numbers plotted as a function of OD409 post-IPTG addition. 
Table 1. SureVector Overlaps (N-terminal Fusions)

Table 2. SV Devices Required to Re-Create the DMRL Biosynthetic Pathway. Each device contains zero, one or two rib genes, and either the kanamycin resistance marker and p15a origin of replication prefabs (labeled "K") or the ampicillin resistance marker and pBR322 origin prefabs (labeled "A"). Single rib gene control plasmids (K1 - K4; A1-A4) require either N- or Cterminal "nnon-coding" parts (NC-N and NC-C, respectively) to assemble complete devices. Zero rib gene control devices ( $\mathrm{K} 5$ and $\mathrm{A} 5$ ) contain both $\mathrm{NC}-\mathrm{N}$ and $\mathrm{NC}-\mathrm{C}$ parts in place of both rib genes to assemble into complete devices. Co-transformation of one " $\mathrm{K}$ " device (e.g. K6 through K9) with one "A" device (e.g. A6 through A9) results in a higher order system expressing either $0,1,2,3$ or 4 rib genes.

Table 3. Combinations of Table 2 Functional and Control Devices Used to Re-Create the DMRL Biosynthetic Pathway System. 


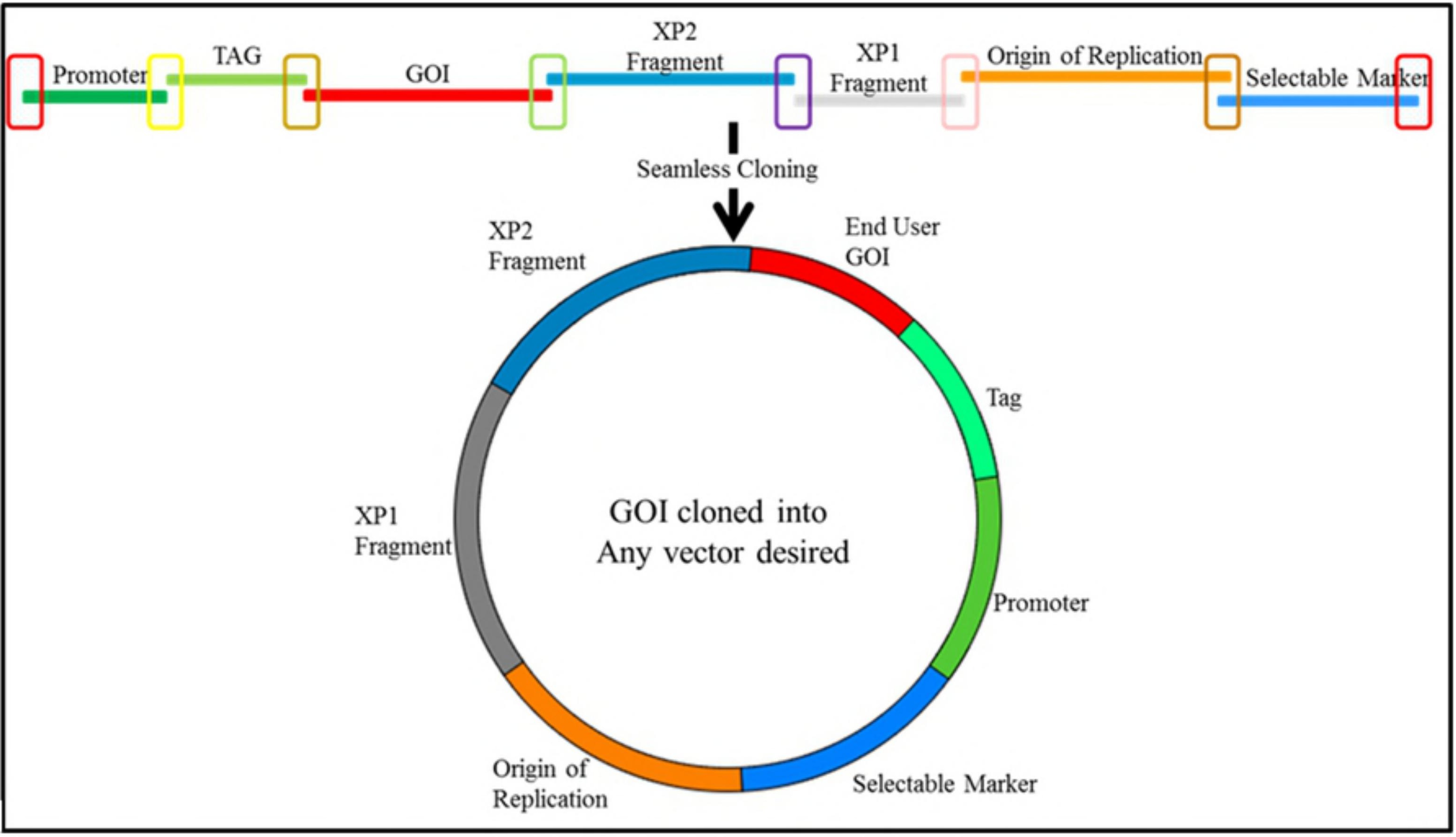


Homologous

\section{Sequences}

Fragment A

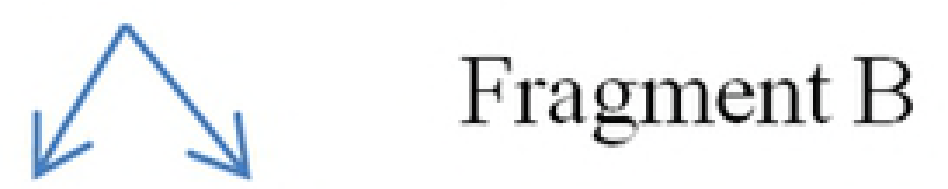

Fragment A

Denature and Re-annealing of homologous Overlaps

Fragment B

Fragment A

Fragment B 


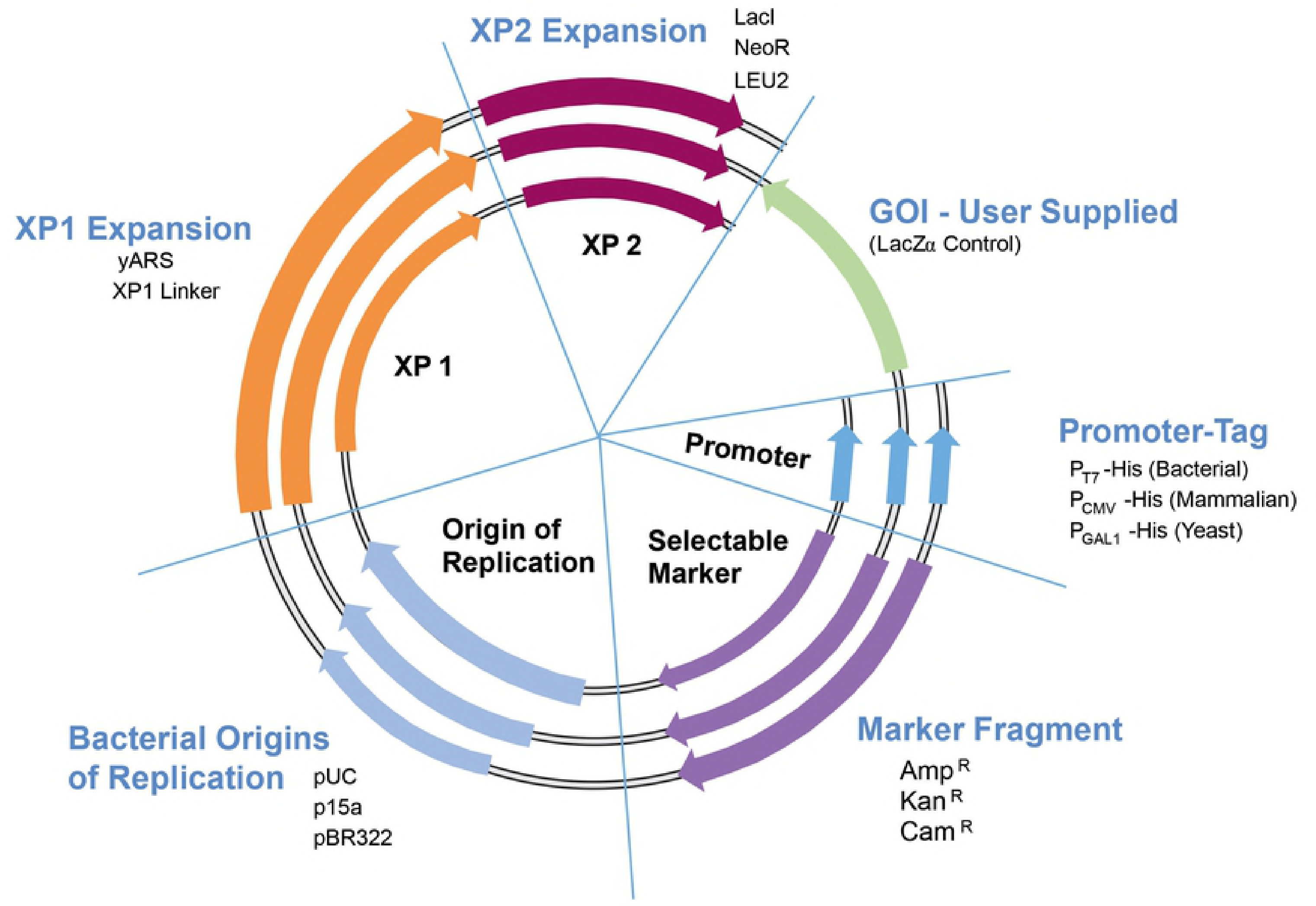




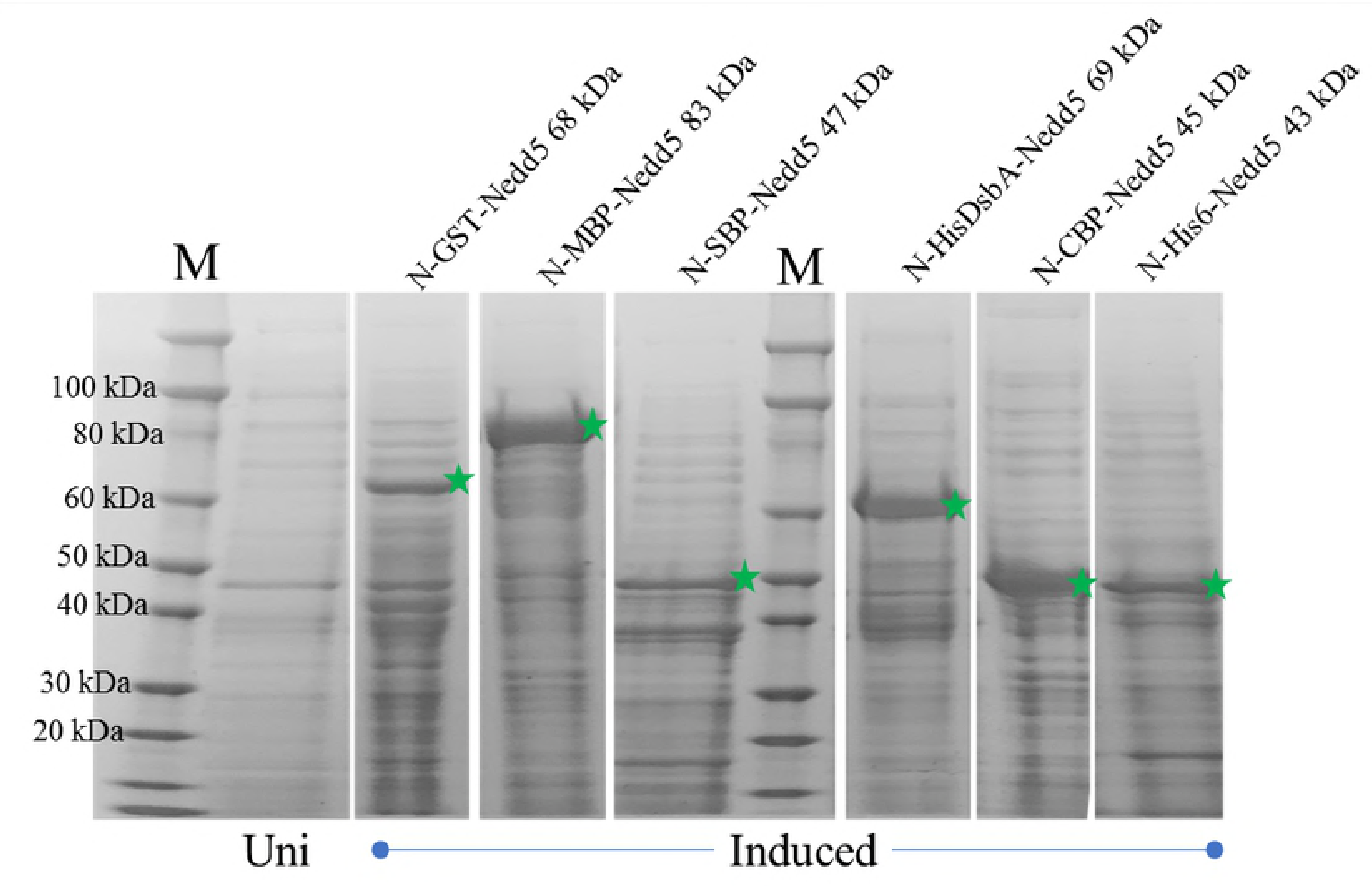




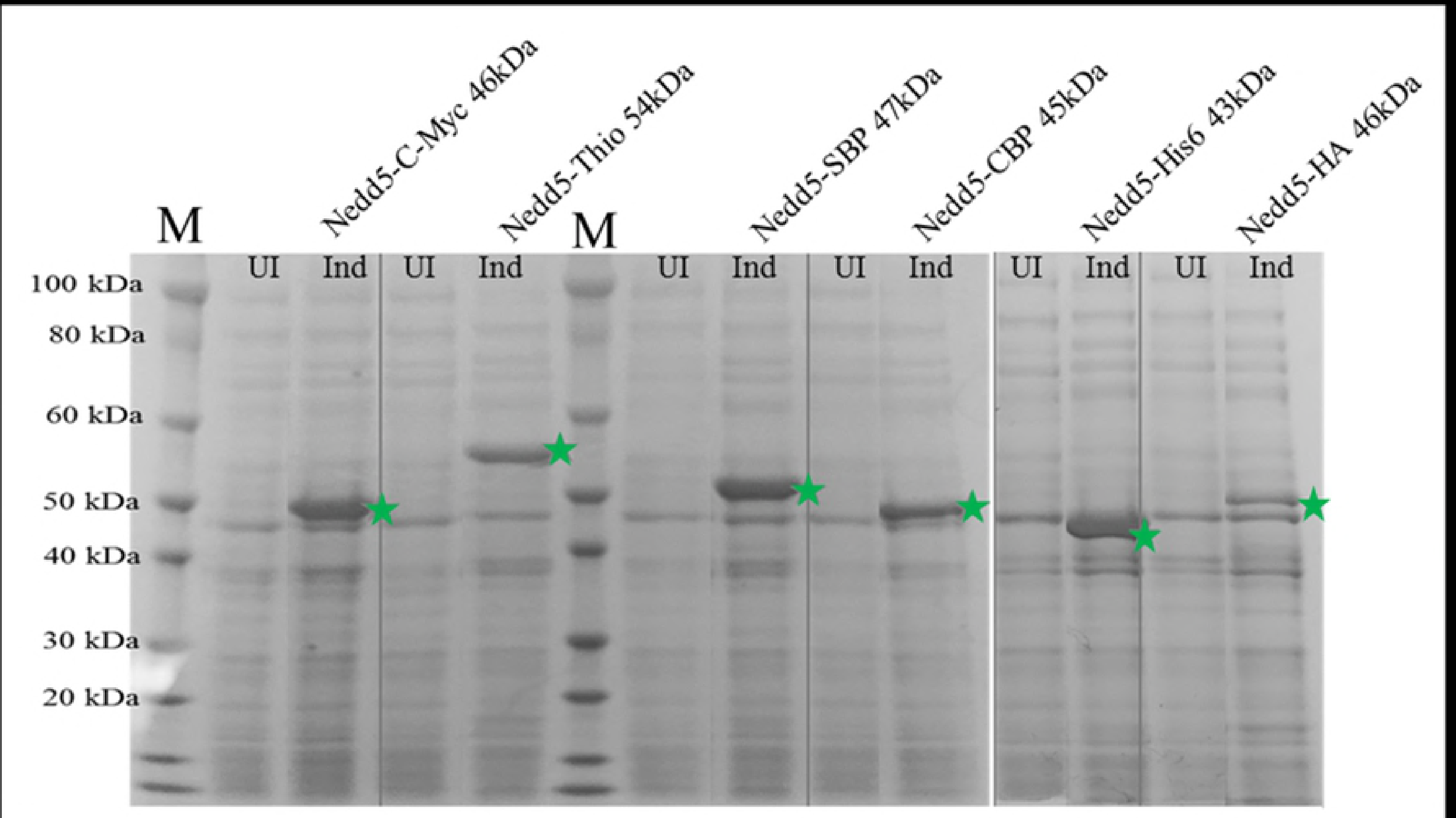




\section{NCR}
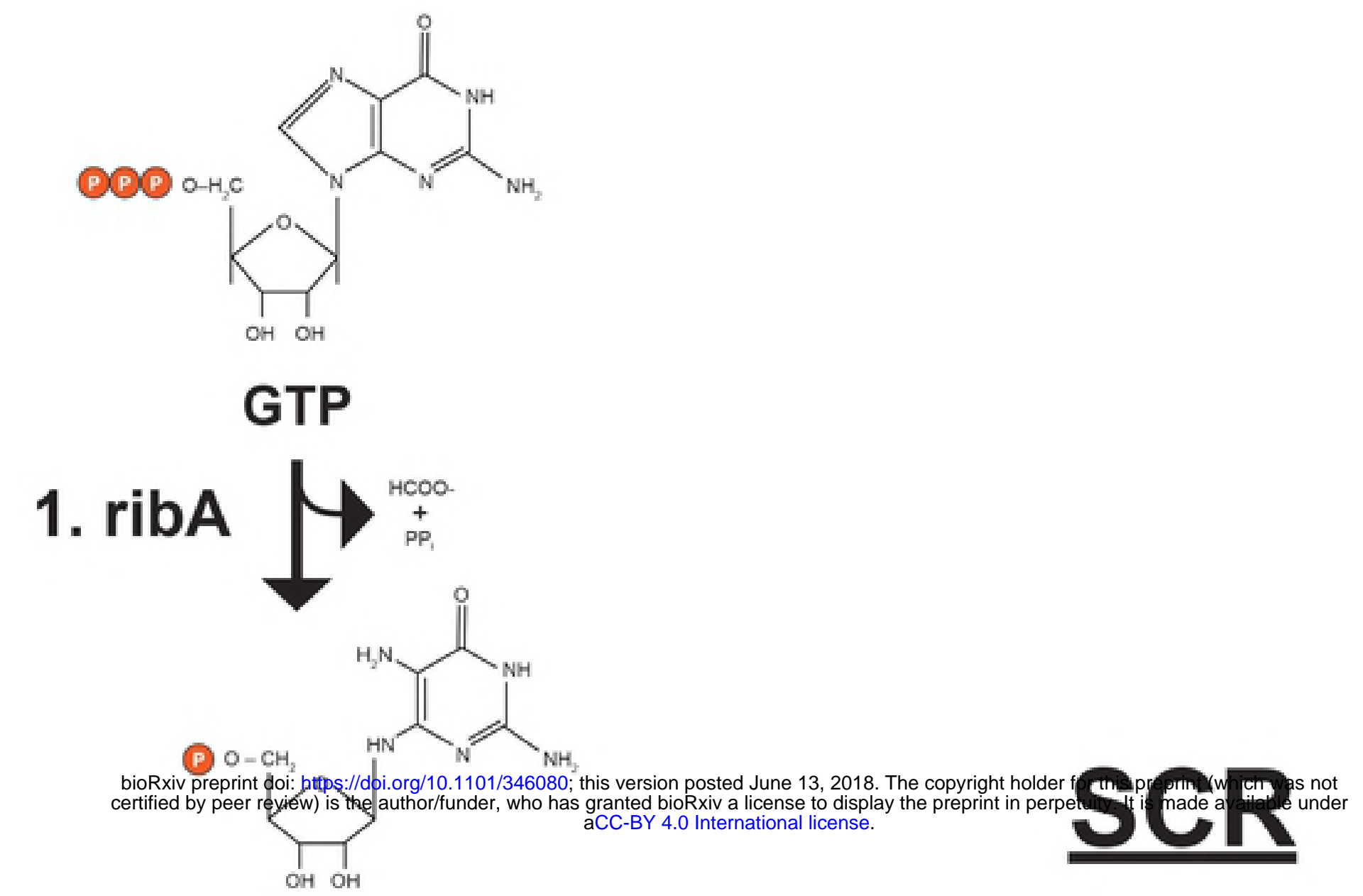

2,5-diamino-6-ribosylamino$4(3 \mathrm{H})$-pyrimidinone5'-phosphate (DARPP)

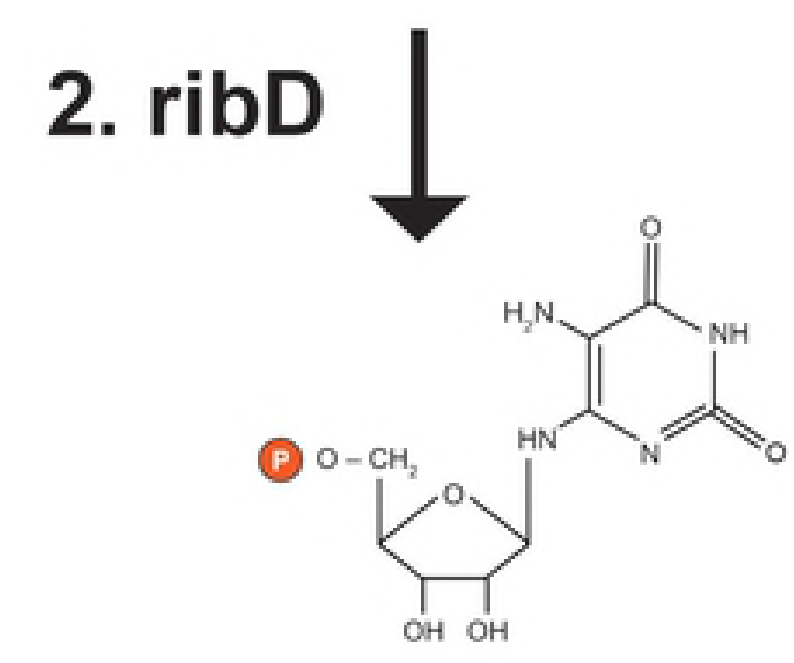

5-diamino-6-ribosylamino$2,4(1 \mathrm{H}, 3 \mathrm{H})$-pyrimidinedione5'-phosphate
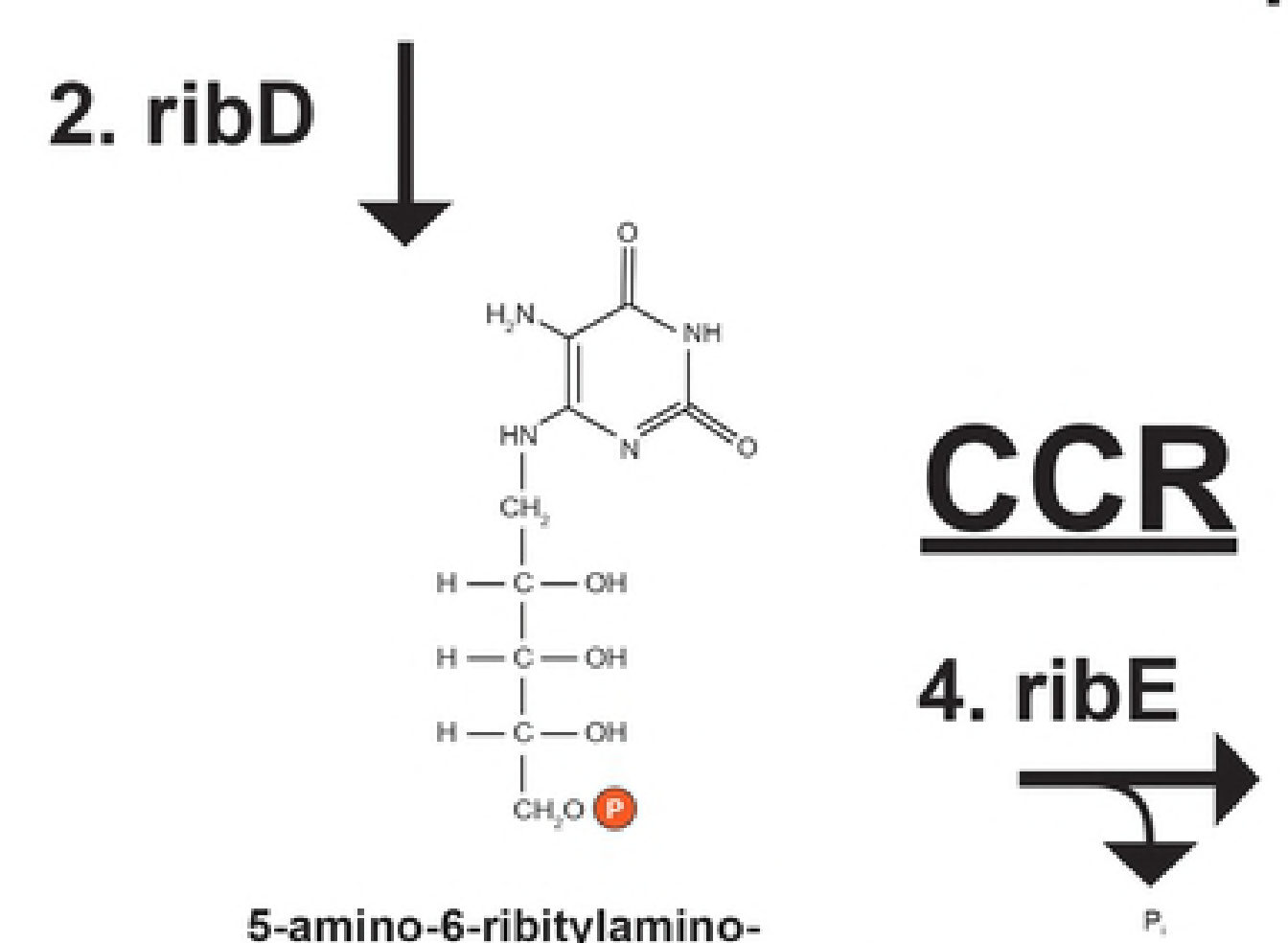

5-amino-6-ribitylamino$2,4(1 \mathrm{H}, 3 \mathrm{H})$-pyrimidinedione$\mathrm{CH}_{2} \mathrm{OH}$
$\mid \mathrm{C}=\mathrm{O}$
$\mid \mathrm{I}$
$\mathrm{H}-\mathrm{C}-\mathrm{OH}$
$\mathrm{I}-\mathrm{C}-\mathrm{OH}$
I $\mathrm{CH}_{2} \mathrm{O} \odot$ Ribulose-5phosphate (R-5'-P)

3. ribB
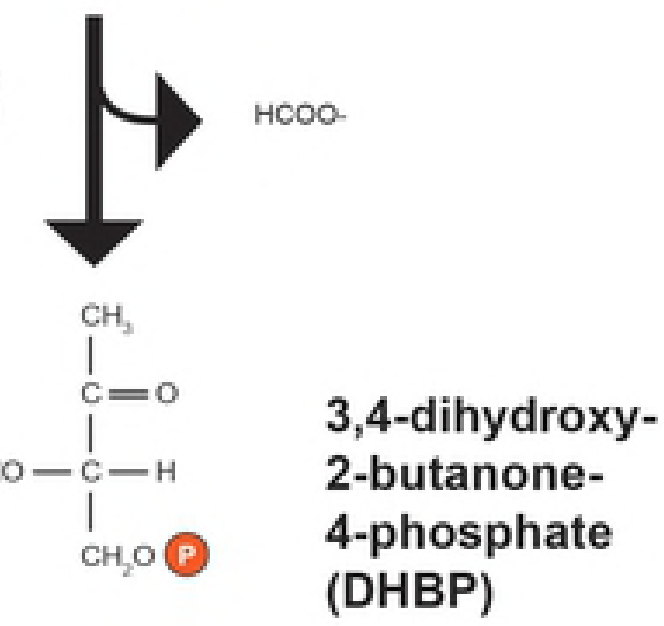<smiles>CC(O)C(=O)O</smiles>

3,4-dihydroxy4-phosphate (DHBP)

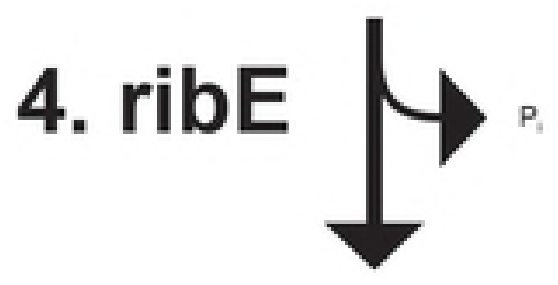<smiles>Cc1nc2c(=O)[nH]c(=O)nc-2n(CC(O)C(O)(O)C(O)(O)CO)c1C</smiles>
5'-phosphate (ARPP) 


\section{Normalized OD409nm}

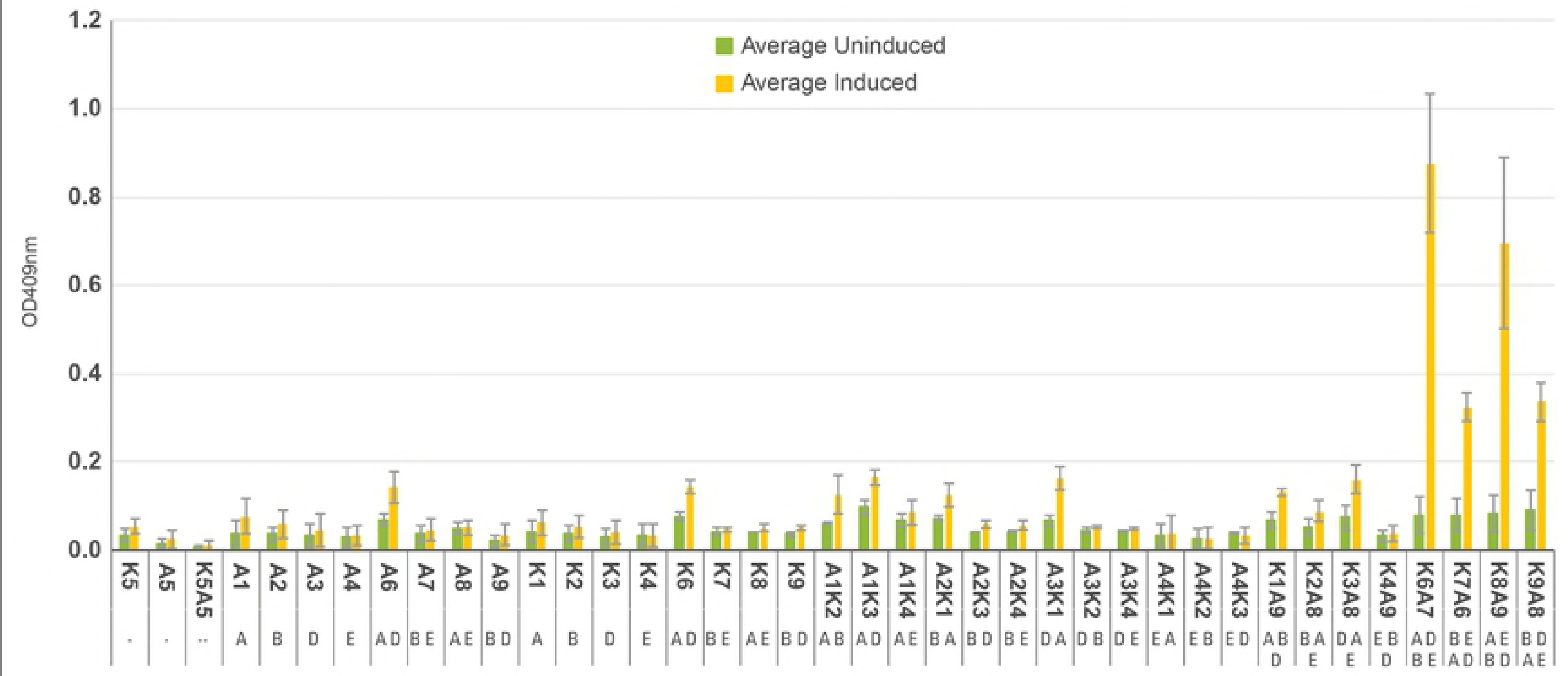

Expression Clone

(rib genes expressed) 


\section{Average A409nm Data}

1.8

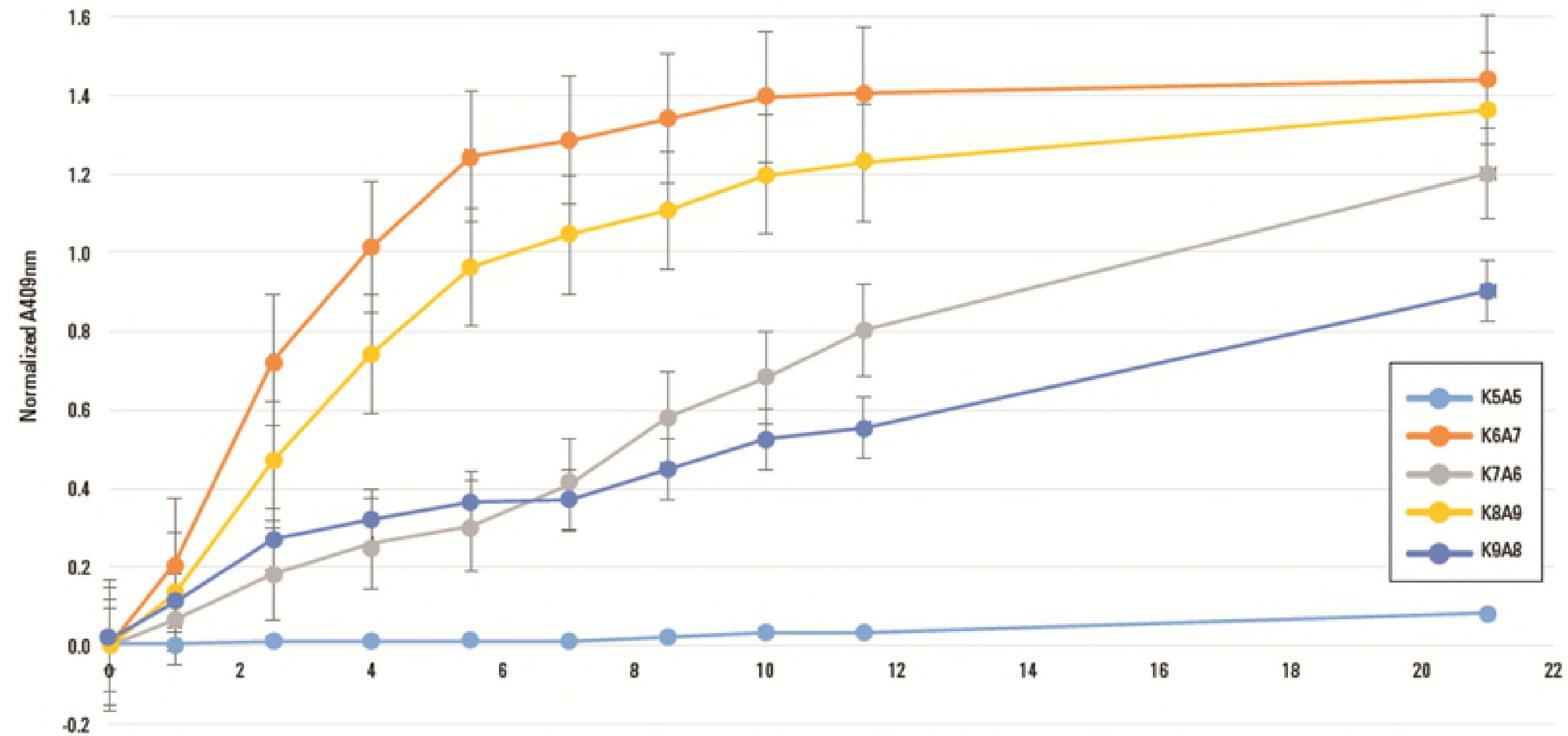

Post Induction Time (hours) 
bioRxiv preprint doi: https://doi org/10.1101/346080; this version posted June 13,2018 . The copyright holder for this preprint (which was not certified by peer review) is the author/funder, who has granted bioRxiv a license to display the preprint in perpetuity. It is made available under aCC-BY 4.0 International license.

Table 1. SureVector Overlaps (N-terminal Fusions)

\begin{tabular}{|c|c|c|c|c|}
\hline \multicolumn{2}{|r|}{5 ' overlap } & \multirow{2}{*}{$\begin{array}{c}\text { Fragment } \\
\text { Promoter }\end{array}$} & \multicolumn{2}{|l|}{ 3' overlap } \\
\hline OV 6 & GCTCATTTCTACAACGCGGCACTTCTCGAG & & ССTTGTTTAACTTTAAGAAGGAGATATACAT & G4S \\
\hline G4S & CCTTGTTTAACTTTAAGAAGGAGATATACAT & $\begin{array}{c}\text { Expression } \\
\text { Tag }\end{array}$ & GGTGGCGGAGGTTCTGGAGGCGGTGGAAGT & OV 5 \\
\hline OV 5 & GGTGGCGGAGGTTCTGGAGGCGGTGGAAGT & $\begin{array}{c}\text { GOI } \\
5^{\prime} \rightarrow 3,\end{array}$ & CATTTGGTTTAGTGTACAATATCTCCTCGAG & OV 4 \\
\hline OV 4 & CATTTGGTTTAGTGTACAATATCTCCTCGAG & $\begin{array}{c}\text { Expansion } \\
\text { Slot } 2\end{array}$ & CAACAGGAGGTGAAGCTGTAACGTCTCGAG & OV 3 \\
\hline OV 3 & CAACAGGAGGTGAAGCTGTAACGTCTCGAG & $\begin{array}{c}\text { Expansion } \\
\text { Slot } 1\end{array}$ & GATTTTGAGACGTGCTCACAGTTTTCTCGAG & OV 2 \\
\hline OV 2 & GATTTTGAGACGTGCTCACAGTTTTCTCGAG & $\begin{array}{c}\text { Origin of } \\
\text { Replication }\end{array}$ & CAGTTCTTCTGGTTGGAGGACTTCCTCGAG & OV 1 \\
\hline OV 1 & CAGTTCTTCTGGTTGGAGGACTTCCTCGAG & $\begin{array}{c}\text { Bacterial } \\
\text { Selectable } \\
\text { Marker }\end{array}$ & GCTCATTTCTACAACGCGGCACTTCTCGAG & OV 6 \\
\hline
\end{tabular}


Table 2. SV Devices Required to Re-Create the DMRL Biosynthetic Pathway. Each device contains zero, one or two rib genes, and either the kanamycin resistance marker and p15a origin of replication prefabs (labeled "K") or the ampicillin resistance marker and pBR322 origin prefabs (labeled “A”). Single rib gene control plasmids (K1 - K4; A1-A4) require either N- or Cterminal "non-coding" parts (NC-N and NC-C, respectively) to assemble complete devices. Zero rib gene control devices (K5 and A5) contain both NC-N and NC-C parts in place of both rib genes to assemble into complete devices. Co-transformation of one " $\mathrm{K}$ " device (e.g. K6 through K9) with one "A" device (e.g. A6 through A9) results in a higher order system expressing either $0,1,2,3$ or 4 rib genes.

\begin{tabular}{|c|c|c|c|c|c|c|}
\hline \multicolumn{7}{|l|}{ Kanamycin/p15a Rib "K” Devices } \\
\hline Device ID & SM & Origin & Promoter & GOI1 & GOI2 & Type \\
\hline K1 & Kan & p15a & T7-His & RibA & NC-C & Control \\
\hline K2 & Kan & p15a & T7-His & RibB & NC-C & Control \\
\hline K3 & Kan & p15a & T7-His & NC-N & RibD & Control \\
\hline K4 & Kan & p15a & T7-His & NC-N & RibE & Control \\
\hline K5 & Kan & p15a & T7-His & NC-N & NC-C & Control \\
\hline K6 & Kan & p15a & T7-His & RibA & RibD & Test Plasmids \\
\hline K7 & Kan & p15a & T7-His & RibB & RibE & Test Plasmids \\
\hline K8 & Kan & p15a & T7-His & RibA & RibE & Test Plasmids \\
\hline K9 & Kan & p15a & T7-His & RibB & RibD & Test Plasmids \\
\hline
\end{tabular}

\begin{tabular}{|c|c|c|c|c|c|c|}
\hline \multicolumn{7}{|l|}{ Ampicillin/p BR322 Rib "A" Devices } \\
\hline Device ID & SM & Origin & Promoter & GOI1 & GOI2 & Type \\
\hline A1 & Amp & pBR322 & T7-His & RibA & NC-C & Control \\
\hline A2 & Amp & pBR322 & T7-His & RibB & NC-C & Control \\
\hline A3 & Amp & pBR322 & T7-His & NC-N & RibD & Control \\
\hline A4 & Amp & pBR322 & T7-His & NC-N & RibE & Control \\
\hline A5 & Amp & pBR322 & T7-His & NC-N & NC-C & Control \\
\hline A6 & Amp & pBR322 & T7-His & RibA & RibD & Test Plasmids \\
\hline A7 & Amp & pBR322 & T7-His & RibB & RibE & Test Plasmids \\
\hline A8 & Amp & pBR322 & T7-His & RibA & RibE & Test Plasmids \\
\hline A9 & Amp & pBR322 & T7-His & RibB & RibD & Test Plasmids \\
\hline
\end{tabular}


Table 3. Combinations of Table 2 Functional and Control Devices Used to Re-Create the DMRL Biosynthetic Pathway System.

\begin{tabular}{|c|c|c|c|c|c|}
\hline \multicolumn{6}{|c|}{ Transformations into BL21(GOLD) } \\
\hline \multicolumn{2}{|c|}{ System } & \multirow{2}{*}{$\begin{array}{l}\text { rib Genes } \\
\text { Expressed }\end{array}$} & \multirow{2}{*}{$\begin{array}{l}\text { Rib genes } \\
\text { Missing }\end{array}$} & \multirow{2}{*}{ Plate on } & \multirow{2}{*}{ Assay } \\
\hline Device 1 & Device 2 & & & & \\
\hline K1 & - & A & $\mathrm{B}, \mathrm{D}$ and $\mathrm{E}$ & Kan & Control \\
\hline $\mathrm{K} 2$ & - & $\mathrm{B}$ & $\mathrm{A}, \mathrm{D}$ and $\mathrm{E}$ & Kan & Control \\
\hline $\mathrm{K} 3$ & - & $\mathrm{D}$ & $\mathrm{A}, \mathrm{B}$ and $\mathrm{E}$ & Kan & Control \\
\hline K4 & - & E & $\mathrm{A}, \mathrm{B}$ and $\mathrm{D}$ & Kan & Control \\
\hline K5 & - & - & $\mathrm{A}, \mathrm{B}, \mathrm{D}$ and $\mathrm{E}$ & Kan & Control \\
\hline K6 & - & A and D & $\mathrm{B}$ and $\mathrm{E}$ & Kan & Control \\
\hline K7 & - & $\mathrm{B}$ and $\mathrm{E}$ & $A$ and $D$ & Kan & Control \\
\hline K8 & - & $\mathrm{A}$ and $\mathrm{E}$ & $\mathrm{B}$ and $\mathrm{D}$ & Kan & Control \\
\hline K9 & - & $\mathrm{B}$ and $\mathrm{D}$ & $\mathrm{A}$ and $\mathrm{E}$ & Kan & Control \\
\hline A1 & - & A & $\mathrm{B}, \mathrm{D}$ and $\mathrm{E}$ & Amp & Control \\
\hline $\mathrm{A} 2$ & - & B & $\mathrm{A}, \mathrm{D}$ and $\mathrm{E}$ & Amp & Control \\
\hline A3 & - & $\mathrm{D}$ & $\mathrm{A}, \mathrm{B}$ and $\mathrm{E}$ & Amp & Control \\
\hline A4 & - & $\mathrm{E}$ & $\mathrm{A}, \mathrm{B}$ and $\mathrm{D}$ & Amp & Control \\
\hline A6 & - & $\mathrm{A}$ and $\mathrm{D}$ & $\mathrm{B}$ and $\mathrm{E}$ & Amp & Control \\
\hline A7 & - & $\mathrm{B}$ and $\mathrm{E}$ & $A$ and $D$ & Amp & Control \\
\hline A8 & - & $\mathrm{A}$ and $\mathrm{E}$ & $\mathrm{B}$ and $\mathrm{D}$ & Amp & Control \\
\hline A9 & - & $\mathrm{B}$ and $\mathrm{D}$ & $\mathrm{A}$ and $\mathrm{E}$ & Amp & Control \\
\hline A5 & - & - & $\mathrm{A}, \mathrm{B}, \mathrm{D}$ and $\mathrm{E}$ & Amp & Control \\
\hline K1 & A9 & $\mathrm{A}, \mathrm{B}$ and $\mathrm{D}$ & E & Kan+Amp & Control \\
\hline $\mathrm{K} 2$ & $\mathrm{~A} 8$ & $\mathrm{~B}, \mathrm{~A}$ and $\mathrm{E}$ & $\mathrm{D}$ & Kan+Amp & Control \\
\hline $\mathrm{K} 3$ & $\mathrm{~A} 8$ & $\mathrm{D}, \mathrm{A}$ and $\mathrm{E}$ & $\mathrm{B}$ & $\mathrm{Kan}+\mathrm{Amp}$ & Control \\
\hline K4 & A9 & E, B and D & A & Kan+Amp & Control \\
\hline K6 & A7 & $\mathrm{A}, \mathrm{D}, \mathrm{B}$ and $\mathrm{E}$ & - & Kan+Amp & Test \\
\hline K7 & A6 & $\mathrm{B}, \mathrm{E}, \mathrm{A}$ and $\mathrm{D}$ & - & Kan+Amp & Test \\
\hline K8 & A9 & A, E, B and D & - & Kan+Amp & Test \\
\hline K9 & $\mathrm{A} 8$ & $\mathrm{~B}, \mathrm{D}, \mathrm{A}$ and $\mathrm{E}$ & - & $\mathrm{Kan}+\mathrm{Amp}$ & Test \\
\hline
\end{tabular}

